\title{
Comparison of statistical and artificial neural network techniques for estimating past sea surface temperatures from planktonic foraminifer census data
}

\author{
Björn A. Malmgren, ${ }^{1}$ Michal Kucera, ${ }^{2}$ Johan Nyberg, ${ }^{1}$ and Claire Waelbroeck ${ }^{3}$
}

\begin{abstract}
We present the first detailed and rigorous comparison of six different computational techniques used to reconstruct sea surface temperatures (SST) from planktonic foraminifer census data. These include the Imbrie-Kipp transfer functions (IKTF), the modern analog technique (MAT), the modern analog technique with similarity index (SIMMAX), the revised analog method (RAM), and, for the first time, a set of back propagation artificial neural networks (ANN) trained on a large faunal data set, including a modification where geographical information was added among the input variables (ANND). By training the techniques on an identical database, we were able to explore the differences in SST reconstructions resulting solely from the use of different mathematical methods. The comparison indicates that while the IKTF technique consistently shows the worst performance, ANN and RAM perform slightly better than MAT and that the inclusion of the geographical information into the training database (SIMMAX and ANND) further improves the accuracy of modern SST estimates. However, when applied to an independent validation data set and an additional fossil data set, the results did not conform to this ranking. The largest differences in the reconstructed SST values occurred between groups of techniques with different approaches to SST reconstruction; that is, ANN and ANND produced SST reconstructions significantly different from those produced by RAM, SIMMAX, and MAT. The application of the various techniques to the validation data set, which allowed comparison of SST reconstructions with instrumental records, suggests that artificial neural networks might provide better paleo-SST estimates than the other techniques.
\end{abstract}

\section{Introduction}

One of the most remarkable consequences of Charles Lyell's uniformitarian principle for the field of paleoceanography has been the opportunity to use the relationship between the distribution of modern faunas and floras and present-day physical conditions in the ocean to reconstruct climatic variations in the Quaternary period. In addition, if this relationship were expressed in the form of a mathematical formula, past climatic variations could be quantified in standard physical scales and units. This appealing prospect was discovered early in paleoceanographical studies, and quantitative reconstruction of Quaternary climate change by means of fossil faunas has become a standard and routinely applied procedure.

Some early attempts at quantifying the relationship between species abundances and observed physical parameters relied on relatively simple mathematical methods [see Hutson, 1977]. The struggle for improvement in the precision of the estimates caused researchers to resort to more complex, often computerintensive, statistical methods. To date, three different approaches have been used to quantify the relationshıp between faunal data and physical properties of the environment. The first approach, known as the Imbrie-Kipp transfer function (IKTF) method [Imbrie and Kipp, 1971], utilizes the standard statistical technique of $Q$ mode principal component analysis to decompose the

\footnotetext{
'Department of Earth Sciences-Marine Geology, Earth Sciences Centre, Göteborg University, Göteborg, Sweden.

${ }^{2}$ Department of Geology, Royal Holloway College, University of London, Egham, Surrey, England, United Kingdom.

${ }^{3}$ Laboratoire des Sciences du Climat et de l'Environnement, Laboratoire Mixte CNRS-CEA, Domaine du CNRS, Gif-sur-Yvette, France.

Copyright 2001 by the American Geophysical Union.

Paper number 2000PA000562.

$0883-8305 / 01 / 2000 \mathrm{PA} 000562 \$ 12.00$
}

variation in the faunal data into a smaller number of variables that are then regressed upon the known physical parameters.

Hutson [1980] developed an alternative approach: His modern analog technique (MAT) does not generate a unique calibration formula between faunal data and physical properties. Instead, this method searches the database of modern faunas for samples with assemblages that most resemble the fossil assemblage. The environment representing the fossil sample is then reconstructed from the physical properties recorded in the best modern analog samples. While the IKTF approach relies upon the assumption that the reconstruction of species' responses to physical parameters will yield the most reliable estimates of past environments, MAT, a true incarnate of Lyell's uniformitarianism, resorts solely to searching for modern situations most similar to that observed in a fossil sample. Significant improvements of this approach include the modern analog with similarity index (SIMMAX) method [Pflaumann et al., 1996] and the revised analog method (RAM) [Waelbroeck et al., 1998].

The third approach, using artificial neural networks (ANN), a branch of artificial intelligence, relies on the sole assumption that there, indeed, is a relationship between the distribution of modern faunas and the physical properties of the environment. ANNs have the ability to overcome problems of fuzzy and nonlinear relationships between sets of input and output variables. This computer-intensive approach is based on an algorithm that has the ability of autonomous "learning" of a relationship between two groups of numbers [Wasserman, 1989; Beale and Jackson, 1990]. Once trained, the neural network serves as a unique transfer function, yet at the same time this highly nonlinear and recurrent function is so complex that it has the ability to simulate a decision algorithm. The utility of ANN in reconstructing past environmental conditions has been recently demonstrated by Malmgren and Nordlund [1997].

The existence of different approaches to sea surface temperature (SST) reconstruction inevitably raises questions of whether there 


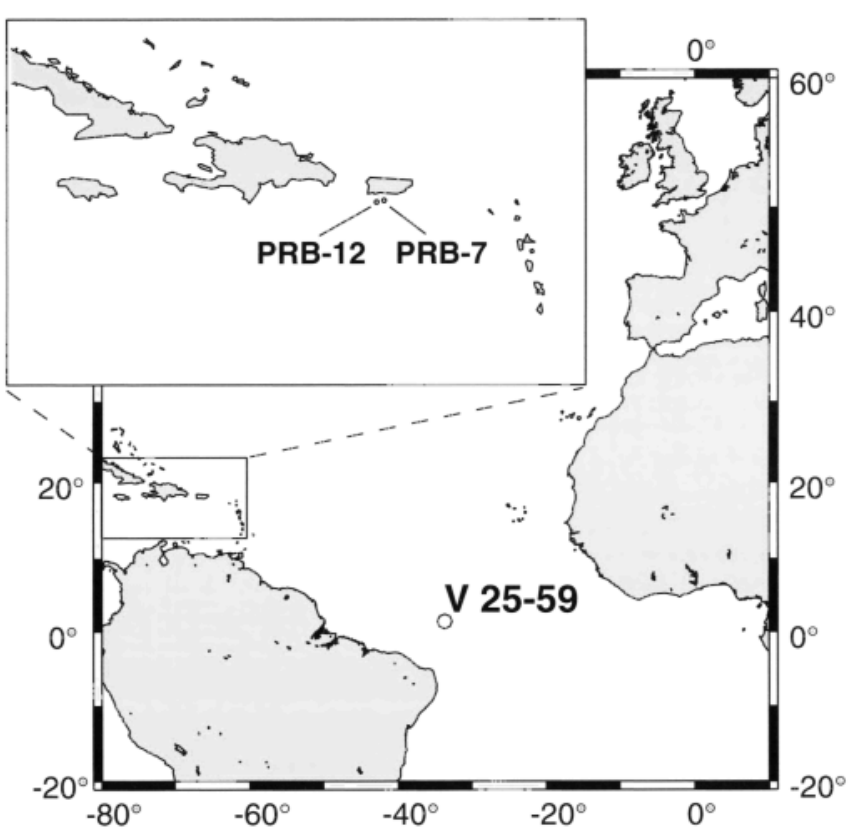

Figure 1. Location of the two Caribbean core tops (PRB-7 and PRB-12) added to the database used by Pflaumann et al. [1996]. The box core PRB-12 was used for the validation of the sea surface temperature (SST) prediction techniques. Also shown is the location of core V 25-59, which was used to examine the differences among the techniques when applied to a fossil data set.

are significant differences among the SST estimates produced by these techniques, how these differences can be explained, and what is the potential influence of the techniques on the validity of the SST estimates. This issue is of great importance since census count-based SST estimates provide the only nongeochemical, and thus truly independent, paleothermometer. Previous attempts to answer these questions have either concentrated only on two of the then available techniques [Prell, 1985; Le, 1992; Ortiz and Mix, 1997] or have presented comparisons of limited statistical validity (different training sets [Waelbroeck et al., 1998] and a small training set [Malmgren and Nordlund, 1997]).

Here we present a detailed and rigorous evaluation of the efficacy of six different techniques used to reconstruct the relationship between modern faunas and SST data, including for the first time a set of ANNs trained on a large faunal data set. The comparison is based on planktonic foraminifer census counts from the Atlantic core top database of Pflaumann et al. [1996], which includes data generated by Climate: Long-Range Investigation, Mapping, and Prediction Project Members [1984]. We compare the performance of the techniques for estimating modern SSTs, and we show the discrepancies among these techniques when applied to independent data, both from recent times, with known temperature variations, and from a Late Pleistocene core with a presumably larger amount of no-analog assemblages.

\section{Material and Methods}

\subsection{Calibration Data Set}

As the basis for the training and performance analysis, census counts of planktonic foraminifera in 740 core tops from the Atlantic Ocean (latitudinal range $87^{\circ} \mathrm{N}-40^{\circ} \mathrm{S}$ ) have been used. The data set consists of 738 core tops from the Atlantic database compiled by Pflaumann et al. [1996] and two additional core tops from the Caribbean Sea (Figure 1 and Table 1), which were included in order to increase the coverage of the tropical Atlantic database.

The census counts of planktonic foraminifera in the two additional samples were generated in the same way as those in the database of Pflaumann et al. [1996]. The counts were based on $>300$ specimens (Table 1) picked from a representative aliquot of the $>150-\mu \mathrm{m}$ sediment size fraction. Twenty-six taxonomic categories of planktonic foraminifera were quantified in each sample using the same criteria as Pflaumann et al. [1996]. Box core PRB12 , from which one of the core top samples derives, was dated by $\mathrm{Pb}-210$ and Cs-137 methods at Risø National Laboratory, Roskilde, Denmark [Nyberg et al., 2001]. The results indicate a relatively uniform sedimentation rate between 3 and $4 \mathrm{~mm} \mathrm{yr}^{-1}$ throughout the top $15 \mathrm{~cm}$ of the core. Each 1-cm-thick interval should thus represent $\sim 3$ years. Therefore the $1-\mathrm{cm}$-thick core top should span an interval between December 1994, when the cores were recovered, and the fall of 1991 . We assume that the sedimentation rate in box core PRB-07 was similar; both cores are located $<1 \mathrm{~km}$ from each other (Table 1).

For the purpose of calibration, "measured" SST data of Pflaumann et al. [1996] were used for both caloric seasons. Throughout this paper, "warm season" SST represents the mean for AugustOctober, while "cold season" SST represents the mean for February-April (and conversely in the Southern Hemisphere). The SST values of Pflaumann et al. [1996] have been extracted from the database of Levitus [1982], which summarizes SST observations over some 100 years and is thus appropriate for the assignment of SST values to deep-sea core top samples. We have used the mean temperature for 0 - to $75-\mathrm{m}$ water depth as a representation of the SST, as Pflaumann et al. [1996] showed that this yields the least standard deviation of SST residuals.

The SSTs for the Caribbean core tops were calculated as arithmetic means of the corresponding temperatures between 1991 and 1994. The temperatures for 1991-1992 were taken from the Comprehensive Ocean-Atmosphere Data Set (COADS) grid of $2^{\circ}$ by $2^{\circ}$ (node at $67^{\circ} \mathrm{W}, 17^{\circ} \mathrm{N}$ ); for $1992-1994$ we used the data from da Silva et al. [1994]. Both databases list the SST without specification of the depth range. At present, the Levitus [1982] 0to 75-m SST and the 0- to 5-m SST off Puerto Rico differ for the warm season by $\sim 0.4^{\circ} \mathrm{C}$, and for the cold season they differ by $\sim 0.1^{\circ} \mathrm{C}$ (Figure 2). In comparison with the 1991-1994 data, the 0to 5-m SST from Levitus [1982] is the same for the warm season, while for the cold season the long-term average is cooler by $\sim 0.2^{\circ} \mathrm{C}$ (Figure 2).

\subsection{Validation Data Set and Fossil Data Set}

The most appropriate way to determine the accuracy of SST reconstructions produced by different techniques is through a

Table 1. Data on the Two Cores Added to the Core Top Database Compiled by Pflaumann et al. [1996]

\begin{tabular}{lcccccrr}
\hline Core & $\begin{array}{c}\text { Water Depth, } \\
\mathrm{m}\end{array}$ & $\begin{array}{c}\text { Latitude, } \\
{ }^{\circ} \mathrm{N}\end{array}$ & $\begin{array}{c}\text { Longitude, } \\
{ }^{\circ} \mathrm{W}\end{array}$ & Dating & WS SST, & \multicolumn{2}{c}{ CS SST, } \\
${ }^{\circ} \mathrm{C}$ & & ${ }^{\circ} \mathrm{C}$ & $N$ \\
\hline PRB-7 & 273 & $17^{\circ} 52.82^{\prime}$ & $66^{\circ} 35.90^{\prime}$ & NA & 28.52 & 26.60 & 382 \\
PRB-12 & 360 & $17^{\circ} 53.27^{\prime}$ & $66^{\circ} 36.02^{\prime}$ & Pb-210 & 28.52 & 26.60 & 334 \\
\hline
\end{tabular}

${ }^{\text {a }}$ Both cores were taken off the coast of Puerto Rico in December 1994. Abbreviations are as follows: WS, warm season; SST, sea surface temperature; CS, cold season; $N$, number of planktonic foraminifera counted in each sample; NA, not available. 


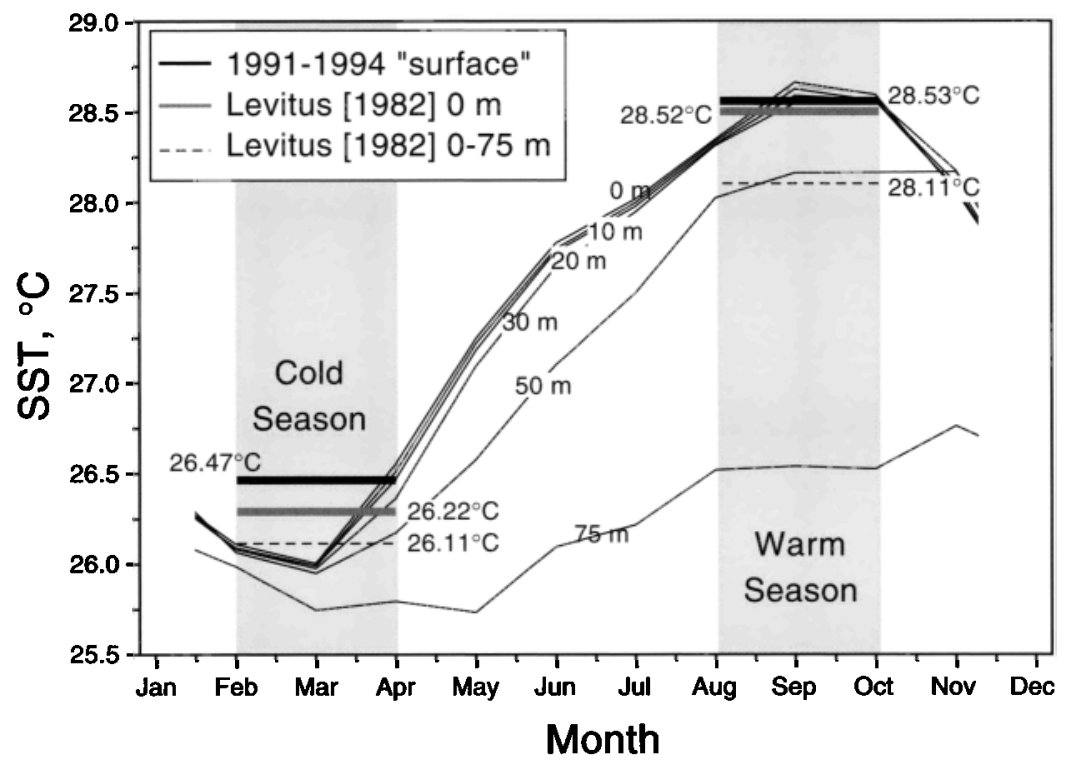

Figure 2. Average seasonal SST variation off Puerto Rico (square grid node at $67^{\circ} \mathrm{W}, 17^{\circ} \mathrm{N}$ ) at different water depths (data from Levitus [1982]). The long-term warm season and cold season averages for 0-m and 0- to 75-m water depths are shown together with the corresponding values for 1991-1994 taken from the Comprehensive OceanAtmosphere Data Set (COADS) and da Silva et al. [1994]. In winter the water column is relatively homogenous, while in summer the surface layer $(0-5 \mathrm{~m})$ is warmer by $\sim 0.4^{\circ} \mathrm{C}$ than the average temperature for the entire upper 0 to $75-\mathrm{m}$ layer.

validation of estimates from an independent set of samples with known SST values. The variability of the validation data set should resemble faunal variation in fossil assemblages. For the purpose of such validation we have selected the Caribbean box core PRB-12 (Table 1). On the basis of $\mathrm{Pb}-210$ and $\mathrm{Cs}-137$ dating [Nyberg et al., 2001] the top $15 \mathrm{~cm}$ of this box core span the last 50 years ( $\sim 1945-1994)$, thus allowing us to compare the estimated SSTs with historical records (COADS and da Silva et al. [1994]). The age model for the top $15 \mathrm{~cm}$ of the core is based on measurements of $\mathrm{Pb}-210$ activity in 12 samples and Cs-137 activity in 14 samples. The error of the age model due to measurement uncertainties is $<10 \%$ (i.e., $<5$ years) for all samples. It should be noted that SST in this data set is defined as "sea surface" temperature, while the prediction techniques are being calibrated on a data set where SST is defined as the mean from $0-$ to $75-\mathrm{m}$ water depth. Thus, as discussed in section 2.1 , because of this discrepancy we may expect a consistent offset of $\sim 0.4^{\circ} \mathrm{C}$ between the predicted and the observed SST for the warm season estimates (Figure 2).

Eight 1-cm-thick samples were taken every $2 \mathrm{~cm}$ from the top 15 $\mathrm{cm}$ of the box core. In each sample, planktonic foraminifer census data were generated by counting between 287 and 430 specimens. No signs of calcite dissolution were observed, which was confirmed by low percentages of planktonic foraminifer fragments in all samples. The major drawback of core PRB-12 is that it derives from an area where SSTs are at the warm end of the SST range in the training data set.

Planktonic foraminifer census data from the low-latitude core V $25-59$ (Figure $1,1^{\circ} 22^{\prime} \mathrm{N}, 33^{\circ} 29^{\prime} \mathrm{W}$ ) were used to assess the differences in SST reconstructions among the techniques when applied to this fossil data set, presumably containing many noanalog samples. The original data set by McIntyre et al. [1989], comprising 45 species and species groups, was culled to include only the taxonomic categories used in the database of Pflaumann et al. [1996]. The faunal variation during the last $\sim 150 \mathrm{kyr}$ recorded in the upper $400 \mathrm{~cm}$ of this core has been the subject of extensive scrutiny [Bé et al., 1976; Waelbroeck et al., 1998]. Census counts for cores PRB-07 and PRB-12, all training and test data sets, and
SST reconstructions in PRB-12 and V 25-59 are available in digital form from the National Oceanic and Atmospheric AssociationNational Geophysical Data Center paleoclimate database (http:// www.ngdc.noaa.gov/paleo/paleo.html).

\subsection{Assessment of Prediction Errors From Modern Data}

Any statistical error rate value based solely on the training data is invariably underestimated [see Birks, 1995]. Therefore to compare the success of particular statistical techniques in learning the relationship between modern faunal data and present-day physical conditions, a split sampling or cross validation of the modern database is necessary. Split sampling involves random division of the modern data into training and test sets, where the training set is used to generate the predictor and the test set is used to compare the predictor's output with the observed values of the environmental variable(s) under study [Birks, 1995]. To obtain a reliable estimate of the error rate, several independent partitions of this type must be performed. When the size of the training data set does not permit split sampling, an alternative technique, known as jackknifing or "leaving one out," may be employed [e.g., Malmgren and Nordlund, 1997]. This technique is inferior to split sampling from all statistical points of view and should be avoided wherever possible [Birks, 1995]. Unfortunately, the use of jackknifing for comparison of SST prediction techniques has been standard for the past decade.

In this study, the data set of 740 samples was split using the partitioning option built into the NeuroGenetic Optimizer (NGO) v2.5 program (BioComp Systems, Inc.) used for the ANN analyses. The larger subset, comprising $80 \%$ of the samples (i.e., 592), was used for training, and the remaining $20 \%$ (148 samples) constituted the test set from which the prediction error of each method was determined. Training of the ANN and all other techniques was performed separately for warm season SSTs and cold season SSTs. To arrive at a reliable estimate of the error rate, the splitting procedure was repeated 10 times for both seasons' SST reconstructions. 
Table 2. Average Configurations of the Back Propagation Networks Trained to Predict Warm Season and Cold Season SSTs From Planktonic Foraminifer Census Counts ${ }^{\mathbf{a}}$

\begin{tabular}{|c|c|c|c|c|c|c|c|}
\hline \multirow[b]{2}{*}{ Method } & \multirow[b]{2}{*}{ SST Season } & \multicolumn{2}{|c|}{ First Hidden Layer } & \multicolumn{2}{|c|}{ Second Hıdden Layer } & \multirow[b]{2}{*}{$2 \mathrm{HL}, \%$} & \multirow[b]{2}{*}{ Output } \\
\hline & & Structure & $N^{\mathbf{b}}$ & Structure & $N^{\mathrm{b}}$ & & \\
\hline ANN & warm & $8 \mathrm{Lo} 3 \mathrm{~T} 5 \mathrm{Li}$ & 16 & $8 \mathrm{Lo} 1 \mathrm{~T} 5 \mathrm{Li}$ & 14 & 70 & $1 \mathrm{Li}$ \\
\hline ANN & cold & $10 \mathrm{Lo} 5 \mathrm{~T} 6 \mathrm{Li}$ & 21 & $9 \mathrm{Lo} 1 \mathrm{~T} 8 \mathrm{Li}$ & 18 & 40 & $1 \mathrm{Li}$ \\
\hline ANND & warm & $12 \mathrm{Lo} 5 \mathrm{~T} 5 \mathrm{Lt}$ & 22 & $6 \mathrm{Lo} 0 \mathrm{~T} 6 \mathrm{Li}$ & 12 & 90 & $1 \mathrm{Li}$ \\
\hline ANND & cold & $11 \mathrm{Lo} 4 \mathrm{~T} 4 \mathrm{Li}$ & 19 & $14 \mathrm{Lo} 0 \mathrm{~T} 12 \mathrm{Li}$ & 26 & 90 & $1 \mathrm{Li}$ \\
\hline
\end{tabular}

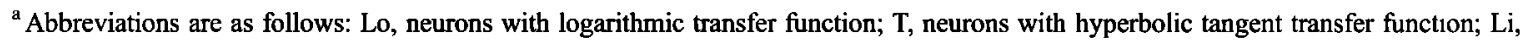
neurons with linear transfer function; 2HL, relative abundance of back propagation networks with two hidden layers.

${ }^{\mathrm{b}}$ The number of neurons in each layer $(N)$ represents the mean of the 10 partitions.

To assess the prediction error of the various techniques, the rootmean-square error of prediction (RMSEP) was computed for each partition as the square root of the sum of the squared differences between the observed and predicted values for all observations from the test set, divided by the number of such observations (i.e., 148 in our case). Error rate calculated in this way is the proper means of "evaluating how a model can be expected to function as a predictive tool" [Birks, 1995, p. 170] and thus constitutes the "appropriate benchmark to compare methods" [ter Braak and van Dam, 1989].

\subsection{Techniques Used}

2.4.1. Imbrie-Kipp transfer functions (IKTF). This technique reduces a matrix of species relative abundances in modern core tops (training set) into a set of statistically independent artificial end-member assemblages by means of $Q$ mode principal components (PC) analysis with varimax rotation [Imbrie and Kipp, 1971]. A limited set of the rotated principal component loadings are then used to construct the transfer function through multiple regression analysis of the relationship between the loadings and individual environmental variables. Usually, the number of principal components (artificial assemblages) used for the calibration is arbitrarily set to a certain number. In our application, we decided to retain the varimax solution, which provided the lowest RMSEP for the independent test set. This criterion provides a well-justified, objective, and repeatable means of selecting the number of end-member assemblages. Thus the number of varimax-rotated PCs ranged among the different partitions between 6 and 16 for warm season SST calibrations, and between 7 and 14 for cold season SST calibrations. Nonlinear multiple regression functions, including all possible squares and cross terms of the original variables (component loadings), were used to calibrate the principal components onto the measured SSTs. The use of curvilinear regression was previously shown to produce lower errors of estimate, although at the cost of higher sensitivity to small changes in the training data set [Le and Shackleton, 1994].

2.4.2. Modern analog technique (MAT). To identify the best analogs in the training set, we used the square chord distance measure of Prell [1985]. A subset of least dissimilar samples from the training set was then used to estimate the temperature of each sample from the test set. In our application the estimated temperature was calculated as an average of the observed temperatures associated with the 10 best analogs weighed by a similarity coefficient [Prell, 1985]. Some authors prefer to cut off all analogs with dissimilarity coefficients higher than a certain value [e.g., Overpeck et al., 1992]. We have experimented with this approach and have concluded that the difference in the temperature estimates is minimal.

2.4.3. SIMMAX. This technique [Pflaumann et al., 1996] follows the general strategy of MAT, but it differs from MAT in the way best analogs are found and treated. In this technique the scalar product of the normalized assemblage vectors is used as a measure of faunal similarity between a sample with unknown SST and samples from the training set. The estimated temperature is calculated as an average of the observed temperatures of the best analogs weighted by the similarity coefficient and the inverse of the geographical distance between each best analog and the unknown sample. The number of best analogs included in the calculation was set to 10 in our application. The choice of the number of best analogs is very subjective; nevertheless, it does not seem to affect the results in a very significant way.

2.4.4. Revised analog method (RAM). In comparison with MAT, the RAM approach [Waelbroeck et al., 1998] includes two significant differences. First, the original training set is artificially expanded by remapping the original data onto a regular grid of environmental variables with a mesh size $\gamma$. For each node on the grid an artificial assemblage is constructed by interpolating assemblages from the training set samples located within a given radius $R$ from the node weighted by their Euclidean distance from the node. Second, the number of best analogs is constrained by a procedure searching for jumps in the dissimilarity coefficient (calculated as in MAT) among the ranked best analogs. A jump is defined by an increase in the dissimilarity coefficient between two of the ranked samples higher than a certain fraction $\alpha$ of the dissimilarity of the last retained best analog. In cases where no jump is encountered, the 10 best analogs are used. In our application the expansion of the training set was done by interpolating in one dimension (either cold season or warm season SST), and both the original training set and the

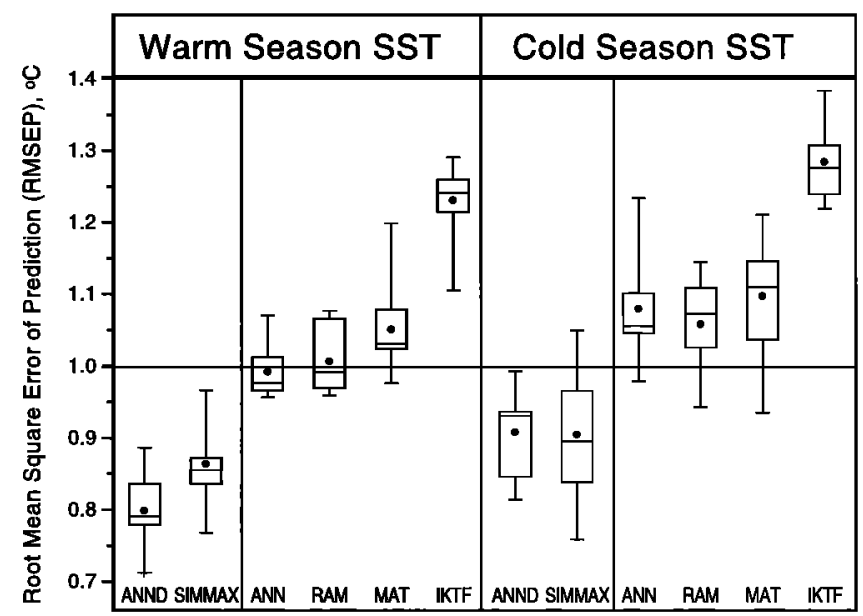

Figure 3. Summary of the prediction errors (expressed as the root-mean-square error of prediction (RMSEP)) produced by the various techniques when applied to the 10 partitions of the training database. The box-and-whiskers plots depict the minimum, 0.25 percentile, median, 0.75 percentile, and the maximum RMSEP values; circles represent the arithmetic average of the 10 partitions for each technique. 


\section{Warm Season SST, ${ }^{\circ} \mathrm{C}$}

\section{Cold Season SST, ${ }^{\circ} \mathrm{C}$}
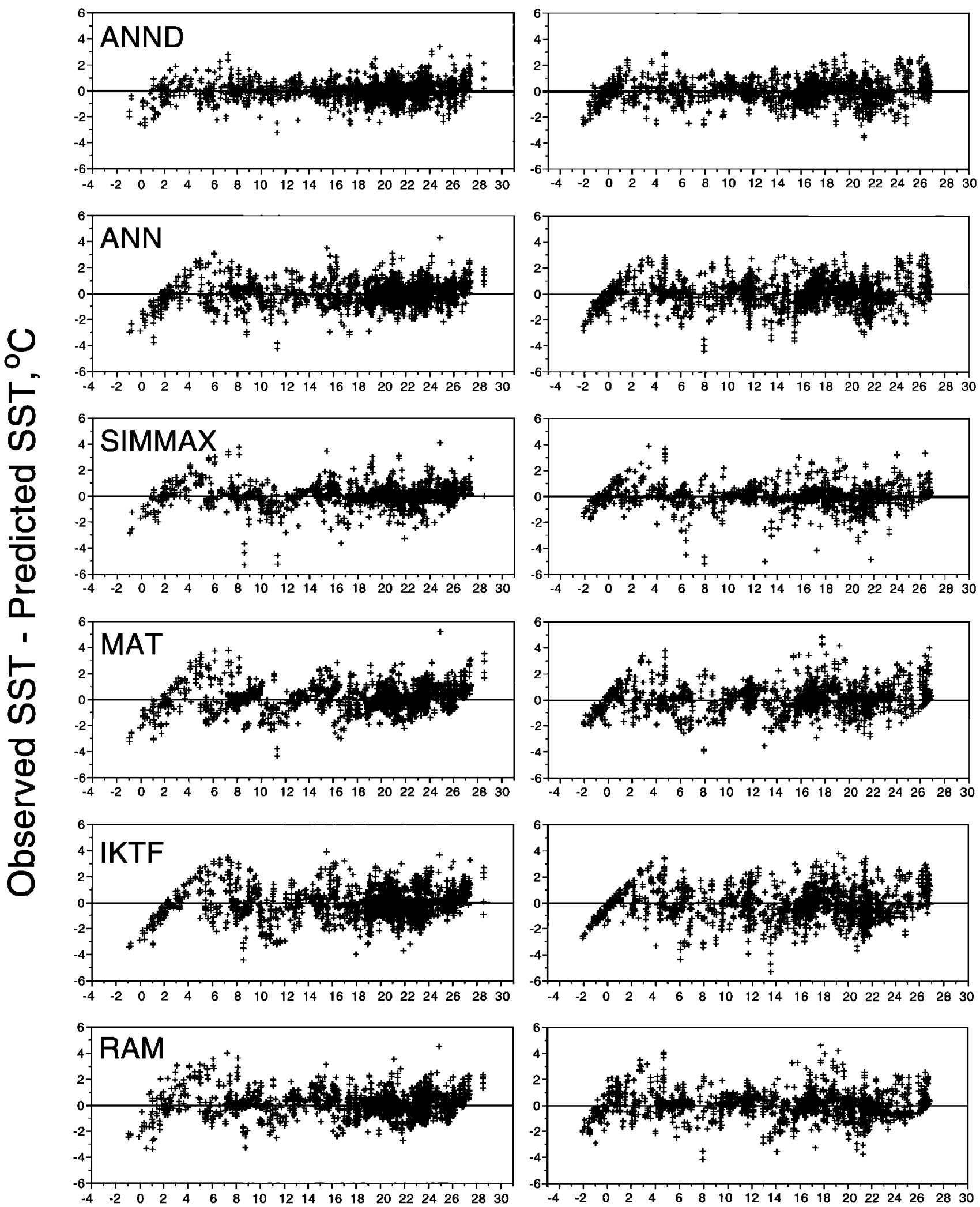

Figure 4. Relationships between observed SSTs and deviations of observed from predicted SSTs for each technique. Data are shown for all 10 partitions (thus $10 \times 148$ comparisons). 

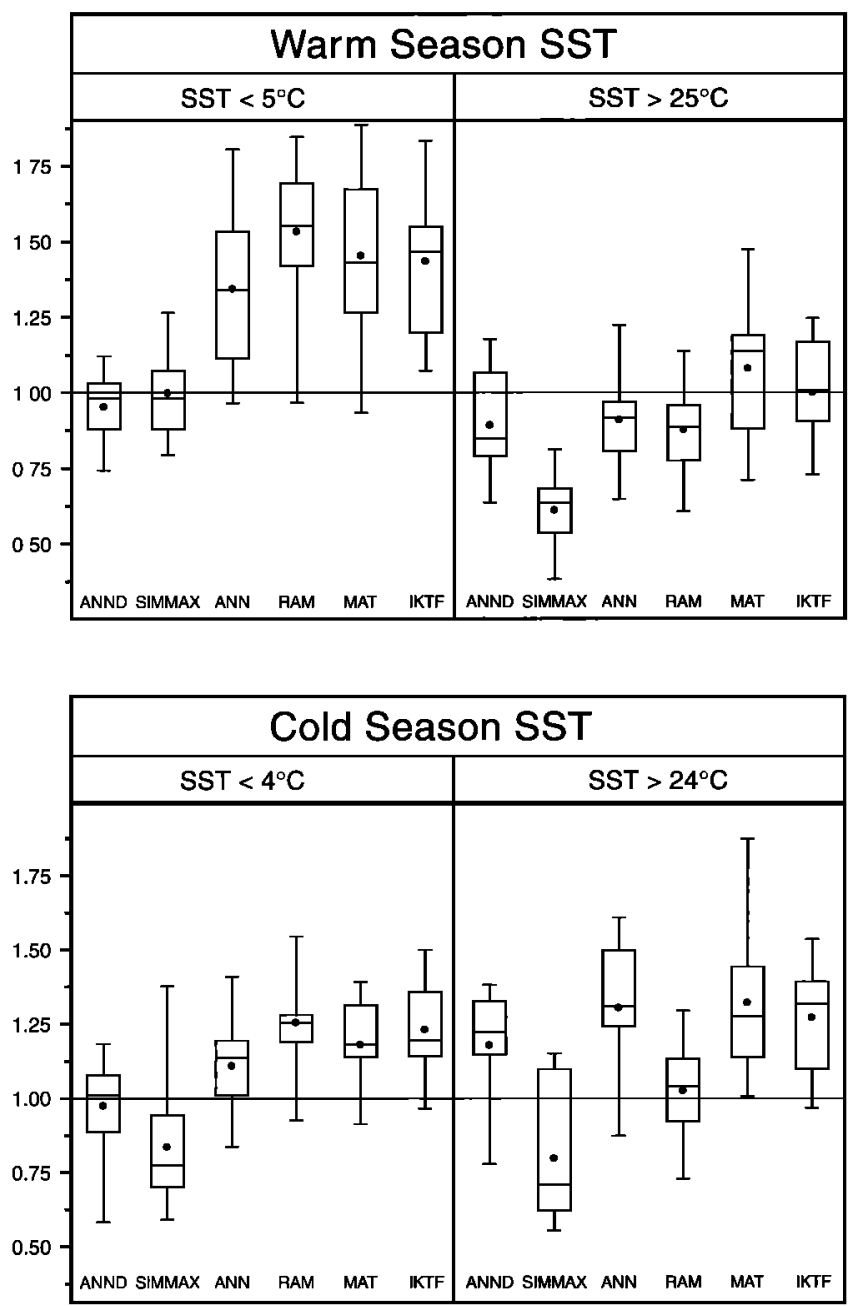

Figure 5. Summary of the prediction errors (expressed as RMSEP in degrees Celsius) produced by the various techniques for the extreme ends of the SST distribution in the 10 partitions of the training data set. The box-and-whiskers plots depict the minimum, 0.25 percentile, median, 0.75 percentile, and the maximum RMSEP values; circles represent the arithmetic average of the 10 partitions for each technique.

interpolated set were used for temperature reconstructions. The parameters we used were $\alpha=0.2$ and $\gamma=R=0.2^{\circ} \mathrm{C}$.

2.4.5. Artificial neural network (ANN). The general principles and architecture of a back propagation (BP) neural network were described by Malmgren and Nordlund [1996, 1997]. In this application a neurogenetic algorithm was used (NGO v2.5 program) that automatically searches for the configuration of the network that produces the lowest error of prediction. Thus the number of hidden layers (one or two), the number of neurons in each layer $(\leq 32)$, and the type of transfer function in each neuron (linear, logarithmic, or hyperbolic tangent) were allowed to vary among the different partitions used for training. For each partition the algorithm proceeded through 50 populations of neural networks with 30 generations in each, thus the total number of net configurations examined was 1500 per partition. Malmgren and Nordlund [1997] noted that a BP network usually reaches the minimum prediction error after $<700$ learning epochs. Our experiments showed that, using the learning ability compensation, the minimum prediction error is reached after $<500$ learning epochs. Therefore the maximum number of learning epochs was set to 500 for each configuration. In addition, a criterion was added that instructed the network to stop learning if no improvement in prediction error occurred after 30 consecutive learning epochs.

2.4.6. Artificial neural network with equatorial distance (ANND). With respect to the amount of information used for training, the SIMMAX approach [Pflaumann et al., 1996] differs from all other methods by including two additional variables to the census counts of the 26 planktonic foraminifer species: the geographical coordinates of the coring sites. To investigate the effect of including such information into databases used for training the BP neural networks, the equatorial distance (directly calculated from latitude) was included as the 27th variable in all partitions. Thereafter, a set of neural networks was trained to predict SSTs from training sets modified in this way. The criteria for network configuration and number of learning epochs were identical to ANN. The average configurations of the trained BP networks for both the ANN and ANND methods are shown in Table 2.

\section{Results}

\subsection{Training}

The results of the calibration and/or training of the various techniques are shown in Figures 3-5 and Table 3. On the basis of their success in predicting modern SSTs from core top samples, the different techniques can be divided into three distinct groups. For all partitions in both the cold season and warm season SST calibration the IKTF technique produced by far the highest RMSEP values (Figure 3). The magnitude of the difference is consistently at least $0.18^{\circ} \pm 0.03^{\circ} \mathrm{C}$, and there is very little overlap between the individual RMSEP values produced by the IKTF and those produced by the other techniques.

ANN, RAM, and MAT seem to yield similar average RMSEP values, though slight differences in the mean values are evident, suggesting that ANN and RAM produce somewhat lower RMSEP than MAT (Figure 3). These differences are, however, negligible when compared with the $>0.18^{\circ} \mathrm{C}$ contrast in RMSEP between these techniques and IKTF.

Both SIMMAX and ANND yield the lowest RMSEP values (Figure 3). For the warm season calibrations, ANND yields slightly lower average RMSEP values than SIMMAX, while for the cold season calibrations the values are similar. Interestingly, the average improvement of the prediction error between these techniques and

Table 3. Mean, Maximum, and Minimum RMSEP Values Produced by the SST Prediction Techniques When Applied to the 10 Partitions of the Training Database ${ }^{a}$

\begin{tabular}{|c|c|c|c|}
\hline & \multicolumn{3}{|c|}{ RMSEP, ${ }^{\circ} \mathrm{C}$} \\
\hline & Mean & Maximum & Minimum \\
\hline \multicolumn{4}{|c|}{ Warm Season SST } \\
\hline ANND & 0.7984 & 0.8864 & 0.7125 \\
\hline SIMMAX & 0.8636 & 0.9662 & 0.7681 \\
\hline ANN & 0.9917 & 1.0703 & 0.9564 \\
\hline RAM & 1.0060 & 1.0770 & 0.9590 \\
\hline MAT & 1.0506 & 1.1991 & 0.9765 \\
\hline IKTF & 1.2305 & 1.2908 & 1.1933 \\
\hline \multicolumn{4}{|c|}{ Cold Season SST } \\
\hline ANND & 0.9081 & 0.9930 & 0.8142 \\
\hline SIMMAX & 0.9045 & 1.0498 & 0.7589 \\
\hline ANN & 1.0794 & 1.2006 & 0.9790 \\
\hline RAM & 1.0581 & 1.1450 & 0.9430 \\
\hline MAT & 1.0969 & 1.2108 & 0.9352 \\
\hline IKTF & 1.2843 & 1.3832 & 1.2195 \\
\hline
\end{tabular}

${ }^{a}$ RMSEP is root-mean-square enror of prediction 

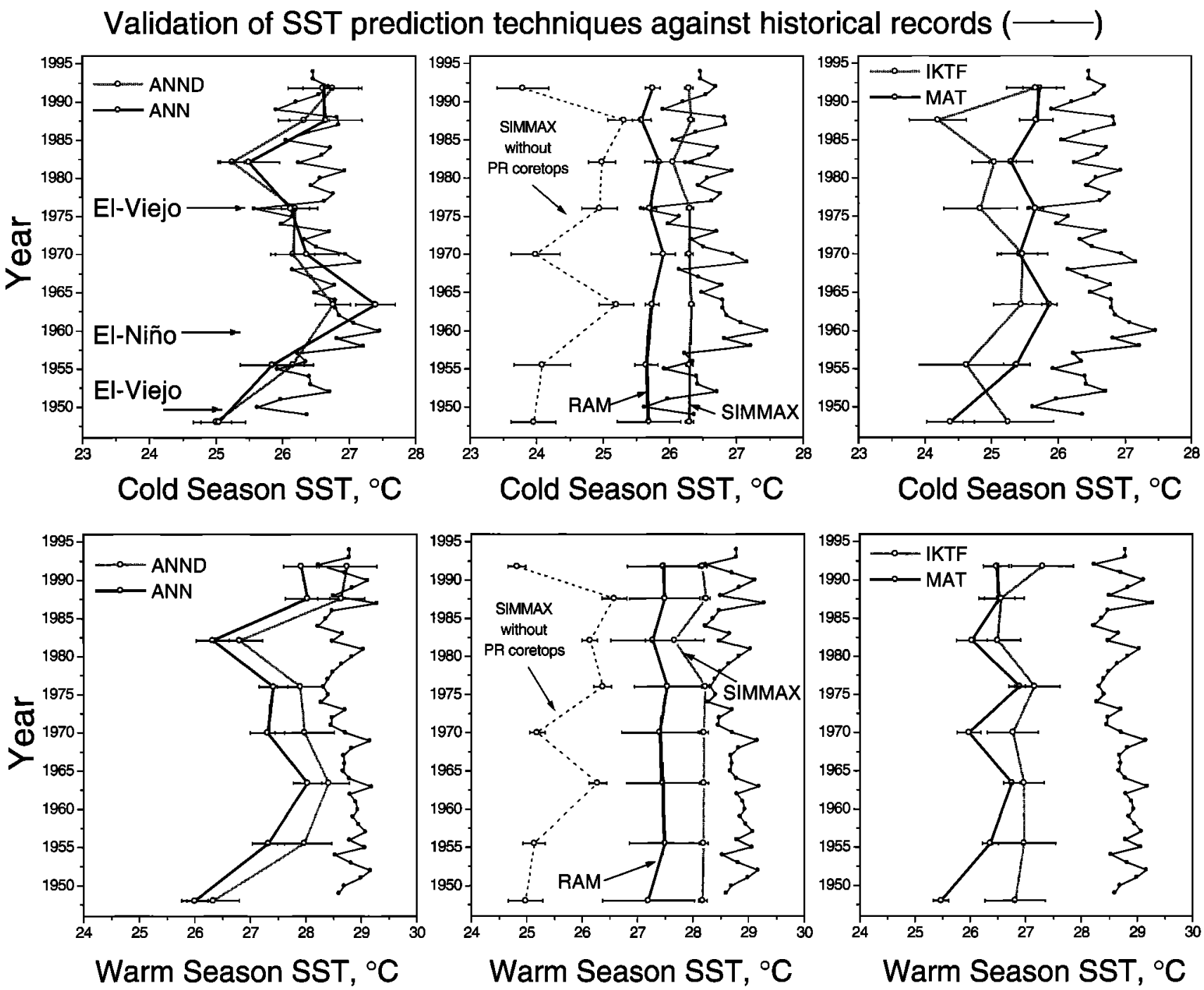

Figure 6. Comparison of reconstructed and measured cold season and warm season SST variation through the time interval recorded in the upper $15 \mathrm{~cm}$ of box core PRB-12. Ten different SST estimates were obtained for each sample by using the 10 different partitions of the training data set to generate the estimates. The mean values and $95 \%$ confidence intervals (horizontal bars) are shown for each sample. Instrumental measurements (fine lines) were compiled from the COADS data set and from da Silva et al. [1994]. Note that the instrumental record comprises "sea surface" temperatures, while the prediction techniques have been trained to estimate average SST from 0 to $75 \mathrm{~m}$. Therefore the warm-season SST estimates are expected to be some $0.4^{\circ} \mathrm{C}$ lower than the instrumental record (see Figure 2).

their counterparts without the geographical information (MAT and ANN) is approximately equal (ANN minus ANND is $0.24^{\circ} \pm$ $0.02^{\circ} \mathrm{C}$ and $0.17^{\circ} \pm 0.03^{\circ} \mathrm{C}$; MAT minus SIMMAX is $0.19^{\circ} \pm$ $0.03^{\circ} \mathrm{C}$ and $0.19^{\circ} \pm 0.04^{\circ} \mathrm{C}$ for warm and cold season SST, respectively; see Figure 3 ).

All six techniques examined were more successful in predicting warm season SSTs than cold season SSTs (Figure 3). The average difference between RMSEP values for the two seasons varied between $0.04^{\circ} \pm 0.04^{\circ} \mathrm{C}$ for SIMMAX and $0.11^{\circ} \pm 0.02^{\circ} \mathrm{C}$ for ANND. However, cold season SST prediction seems to be more sensitive to small changes in the training data set, as implied by the larger variability among the RMSEP values from individual partitions (Figure 3).

Whether the various techniques produce consistent prediction error throughout the SST range in the test sets can be addressed by examining the distribution of the residuals (Figure 4) and by calculating RMSEP for both extremes of the SST range (Figure
5). The most prominent feature in the plots of the residuals (i.e., the predicted minus the observed SST values) is the presence of a "tail" at the cold end of the SST range (Figure 4). This feature translates the fact that the estimated SSTs are systematically warmer than the coolest observed SSTs and are colder than the immediately adjacent cold SSTs. This phenomenon is caused by the extremely low diversity of polar planktonic foraminifer faunas, which show decreasing change in composition with decreasing SST values [see also Pflaumann et al., 1996]. The plot of the residuals in Figure 4 also reveals that all the methods consistently underestimate the warmest SSTs.

The RMSEP values calculated for the extremes of the SST range $\left(<5^{\circ} \mathrm{C}\right.$ and $>25^{\circ} \mathrm{C}$ for warm season and $<4^{\circ} \mathrm{C}$ and $>24^{\circ} \mathrm{C}$ for cold season) reveal several interesting features about the SST predictions (Figure 5). In the warm season SST predictions all techniques were more successful in estimating the warm end SSTs and less successful in estimating the cold end SSTs. As expected from the 
distribution of the residuals in Figure 4, ANND and SIMMAX yielded much lower RMSEP for the cold end SST predictions, most probably as a consequence of the substitution of faunal variation in the cold end samples by the geographical information. In the cold season SST predictions all techniques were either equally successful for both ends of the SST range or, in some cases, were more successful in estimating the cold end SSTs and were less successful in estimating the warm end SSTs.

The performance of some techniques in extremes of the SST range did not conform to the general ranking based on the prediction errors from the entire SST range (Figure 3 and Table 3). Thus, being very successful in predicting SST in both extremes of the SST range, SIMMAX must inevitably produce larger errors in the remaining part of the SST range. The RAM technique produced the highest RMSEP values in the cold end predictions for both seasons and the second lowest RMSEP values for the warm end predictions for both seasons. Consequently, it appears that this technique is more efficient in predicting warmer SSTs. Contrary to the general ranking, in the extreme end SST predictions the IKTF technique produced similar or even lower RMSEP values than ANN and MAT. This implies that IKTF yields a large error of prediction throughout the SST range, while ANN and MAT are more successful in predicting SSTs between the extremes of the SST range.

\subsection{Validation}

The SST in the Caribbean Sea south of Puerto Rico varied significantly over the past $\sim 50$ years (Figure 6 ). The variation appears largely decoupled between warm season and cold season SSTs. The cold season SST signal manifests larger variability with SST values between $25.5^{\circ}$ and $27.5^{\circ} \mathrm{C}$. The warm season SST signal shows less variability with values between $28.2^{\circ}$ and $29.2^{\circ} \mathrm{C}$. The highest warm season SST in the training data set was $28.54^{\circ} \mathrm{C}$. This implies that a certain part of the warm season SST variation falls outside of the range represented in the training data set.

With respect to the cold season SST reconstruction the ANN and ANND methods yielded exceptional results, with reconstructed SSTs matching the absolute values and general trends in the instrumental record. Both methods succeeded in reconstructing the most prominent features of the recorded cold season SST series: the unusually cold winters of the El Viejo years 1950 and 19731975 and the extremely warm winters of the El Niño years 19571958 (Figure 6). Despite the substantial difference in their ability to reconstruct modern SST, because of the addition of the geographical information in ANND, both methods yielded virtually identical cold season SST reconstructions for core PRB-12.

SIMMAX and RAM methods succeeded in reconstructing the absolute values of the recorded cold season SST. However, both methods failed to reconstruct the SST variation. This is especially true for SIMMAX, which only produced reasonable SST reconstructions when the two Caribbean core tops were retained in the training database. Because of the close proximity of both core tops to PRB-12 (the PRB-12 core top was artificially set to be $1 \mathrm{~km}$ away; retaining the original distance would mean that the reconstructed SST would have been equal to the core top value for all samples [see Pflaumann et al., 1996]), the reconstructed SST never deviated from the values recorded in these core tops. When these core tops were removed from the training database, the SST reconstruction departed from the record more than the results of all the other techniques (Figure 6). MAT and IKTF failed to reconstruct even the absolute values of the SST variation. The reconstructed SSTs are lower than the recorded values by as much as $1^{\circ}-2^{\circ} \mathrm{C}$ (Figure 6). The SST variation reconstructed by MAT seems to conform better to the variation in the instrumental record than the SST variation reconstructed by IKTF, which does not seem to follow the record at all.

The warm season SST reconstructions produced by all methods appear to follow the cold season SST reconstructions, offset by
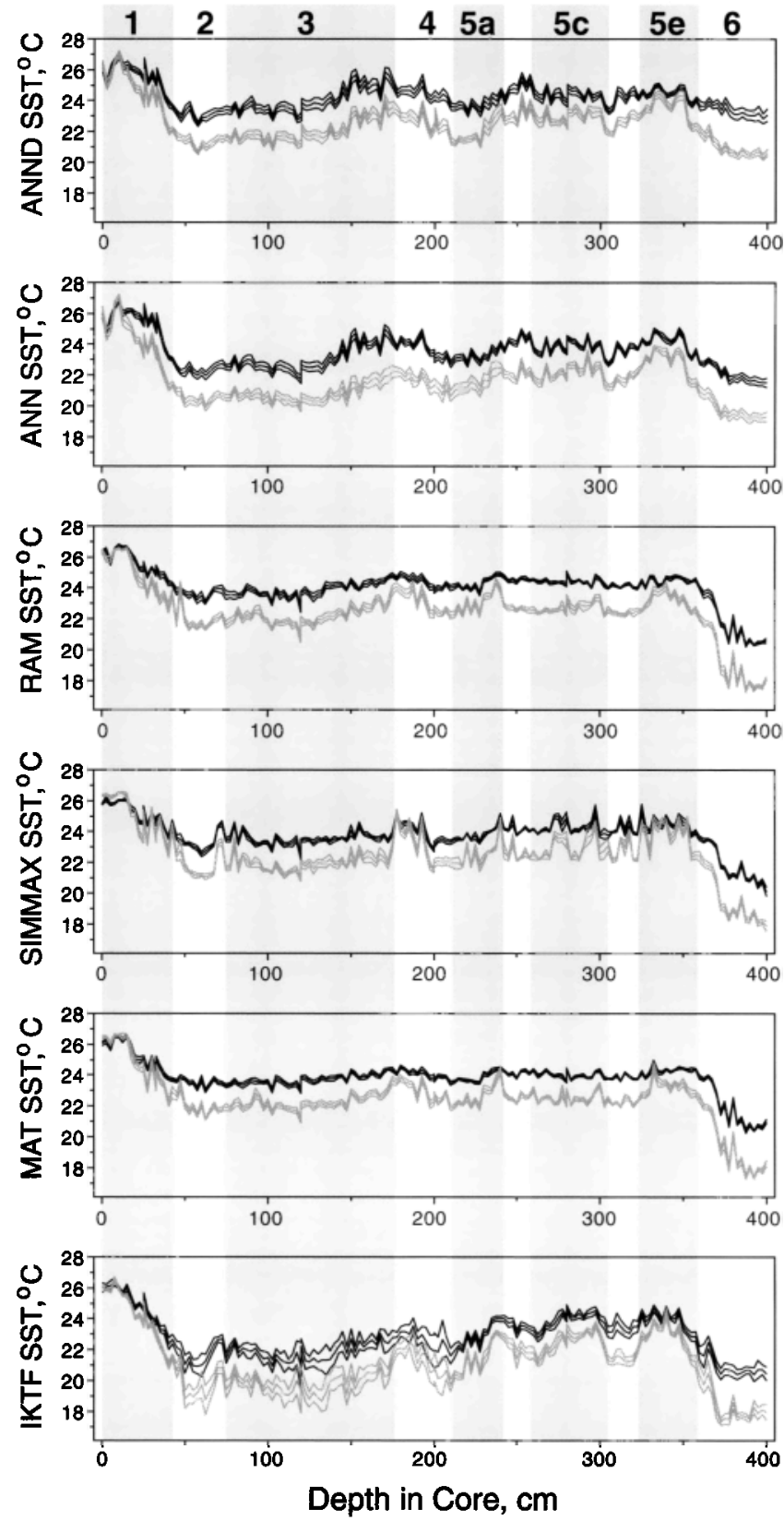

Figure 7. Warm season and cold season SST reconstructions in core V 25-59 derived from the different techniques. Bold lines represent mean values of the 10 estimates produced by each technique; fine lines envelop $95 \%$ confidence intervals. The inferred ranges of oxygen isotope stages 1 through 6 follow McIntyre et al. [1989]. The SST reconstructions for the core presented here depart substantially from those in previous studies [Bé et al., 1976; McIntyre et al., 1989; Waelbroeck et al., 1998]. This fact can be best explained by the choice of a very different training database. While all the previous studies based the reconstructions on global databases including samples from the Pacific and Indian Oceans, our database only includes samples from the Atlantic Ocean.

some $1.5^{\circ} \mathrm{C}$ toward warmer temperatures. Once the expected $0.4^{\circ} \mathrm{C}$ shift due to the difference in the SST definition between the instrumental record and the training data set is taken into account, one could argue that the predictions by ANND, ANN, SIMMAX 
(with Caribbean core tops), and RAM approach the absolute values of the instrumental record. However, none of the methods fully succeeded in reconstructing the absolute values in the record. This probably reflects the fact that the recorded warm season SST values were above the range of the training database.

\subsection{Application to the Fossil Record}

In order to assess the potential differences among the SST reconstruction techniques when applied to a large fossil data set, the SST variation during the last $\sim 150 \mathrm{kyr}$ was reconstructed from census counts in tropical Atlantic core V 25-59 (Figure 7). Although the general pattern of variation is similar for all six SST reconstructions, there are significant differences. We will discuss three aspects of the SST reconstructions where these differences are most marked: (1) the pattern and magnitude of the deglacial warming during Termination I (the transition from oxygen isotope stage (OIS) 2 to 1), (2) the SST variability between OIS 2 and OIS 5 , and (3) the reconstructed SST values for the glacial OIS 6.

According to both ANN and ANND, Termination $I$ in the tropical Atlantic was relatively abrupt, with the Last Glacial Maximum ocean being some $4^{\circ} \mathrm{C}$ (warm season) to $5^{\circ} \mathrm{C}$ (cold season) colder than during the Holocene (Figure 7). All three modern analog technique-based methods (RAM, SIMMAX, and MAT) reconstructed Termination I as being more gradual, with a smaller magnitude of the deglacial warming $\left(\sim 3^{\circ} \mathrm{C}\right.$ for warm season SST and $\sim 4.5^{\circ} \mathrm{C}$ for cold season SST). The IKTF SST reconstruction also appears to suggest that Termination I was gradual, but the magnitude of the deglacial warming was much larger $\left(\sim 5^{\circ} \mathrm{C}\right.$ for warm season SST and $7^{\circ} \mathrm{C}$ for cold season SST). It should be noted that SST values produced by IKTF for the remaining part of the core (OIS 2-6) are much lower (by almost $2^{\circ} \mathrm{C}$ ) than those produced by the other techniques.

With respect to SST variation during the interval from OIS 2 to OIS 5, the ANN and ANND techniques yielded almost identical results, suggesting variations of $\sim 4^{\circ} \mathrm{C}$ in both the cold season and warm season SST (Figure 7). In sharp contrast, the SST variability in this interval reconstructed by RAM, SIMMAX, and MAT is much weaker (at most $2.5^{\circ}-3^{\circ} \mathrm{C}$ ) with most of the variation in cold season SST. Similar to ANN and ANND, IKTF also reconstructed significant variation between OIS 2 and OIS 5 in both cold season and warm season SST. Interestingly, the $95 \%$ confidence intervals for the SST reconstruction in OIS 2-4 are much greater than in any of the other techniques. This suggests that the IKTF SST reconstructions for this interval in core V 25-59 are highly unstable (i.e., a small change in the training database causes large changes in the reconstructions).

The most obvious difference among the SST reconstructions concerns the SST values for OIS 6, where ANN and ANND yielded SSTs $2^{\circ}-3^{\circ} \mathrm{C}$ higher than all the remaining techniques (warm season SST of $22^{\circ}-23^{\circ} \mathrm{C}$ versus $20^{\circ}-21^{\circ} \mathrm{C}$ and cold season SST of $20^{\circ}-21^{\circ} \mathrm{C}$ versus $18^{\circ}-19^{\circ} \mathrm{C}$ ) and thus were similar to OIS 2 SSTs. This part of the core (below $\sim 360 \mathrm{~cm}$ ) shows signs of calcite dissolution [Bé et al., 1976]. Extremely low SST reconstructions, especially for the cold season, have been produced by all techniques previously used for this core (IKTF [Bé et al., 1976; McIntyre et al., 1989] and RAM and MAT Waelbroeck et al., 1998]). Thus it appears that the artificial neural networks significantly differ from all the other SST reconstruction methods by their way of treating no-analog samples.

\section{Discussion and Conclusions}

\subsection{Reconstructing Modern SST}

The main conclusions drawn from the RMSEP values for each technique seem to confirm previously published results. The superiority of all other techniques over IKTF when predicting modern SSTs has been noted in numerous studies [e.g., Pflaumann et al., 1996; Malmgren and Nordlund, 1997; Ortiz and Mix, 1997; Waelbroeck et al., 1998]. Here we not only confirmed this pattern but also showed that IKTF SST reconstructions for the validation data set departed most from the instrumental record. Similarly, the SIMMAX technique was considered to yield better predictions of modern SST than MAT [Pflaumann et al., 1996], which is clearly confirmed by the results of this study (Figure 3 and Table 3 ). This is not surprising given the fact that the technique enlarges the training database by an additional variable, which is highly correlated with modern SST. An identical improvement in RMSEP is achieved when geographical information is included as an additional variable into the training data set for the BP neural network (ANND). Obviously, the addition of geographical information imposes severe limits on the use of such techniques: The general assumption that the relationship between variables in the training set and SST remain the same through time can be justified for foraminifer species but certainly not for geographical information [see Waelbroeck et al., 1998]. Therefore SIMMAX and ANND should not be used for SST reconstructions beyond very recent times (i.c., late Holocene).

Unlike the large differences in RMSEP described above, ANN and RAM seem to yield only a slightly lower RMSEP than MAT (Figure 3 and Table 3 ). The average difference is very small and not statistically significant. Thus, although ANN and RAM were considered to produce significantly better results than MAT in previous comparisons [Malmgren and Nordlund, 1997; Waelbroeck et al., 1998], our study does not seem to support this conclusion.

\subsection{Differences Among SST Predictions}

The direct comparison of reconstructed SSTs with an instrumental record indicates that ANN and ANND yielded the best SST estimates (Figure 6). The application of the techniques to the validation data set also shows that differences in reconstructed SST do not conform to the performance of the techniques in estimating modern SST (Figure 3 and Table 3). Although ANND and SIMMAX produced the lowest RMSEP for modern samples, the SST reconstructions by ANND were almost identical to those produced by ANN, while SIMMAX estimates resembled much more the SST estimates by RAM. To document this relationship in a quantitative manner, we have performed a $Q$ mode principal component analysis of the SST reconstructions by the different techniques for the validation data set (Figure 8). The analysis demonstrates that the predictions produced by ANN and ANND are very similar to each other while being distinct from those of the other techniques. This conclusion is further supported by the results of SST reconstruction in core V 25-59. A $Q$ mode principal component analysis of SST reconstructions in this core (Figure 8) shows that ANN and ANND produced similar SST estimates, different from those produced by MAT, SIMMAX, and RAM.

The difference in SST estimates between modern analog techniques and artificial neural network techniques provides a powerful tool for assessing the reliability of SST estimates in the fossil record. This concept was originally proposed by Hutson [1977]: When techniques based on different approaches yield similar results, the estimates can be considered more reliable. On the other hand, when different techniques produce widely diparate results, the estimates are less reliable, either because of the presence of no-analog samples or as a result of secondary modification of the foraminiferal assemblage by calcite dissolution or other processes. Until now, there was no alternative to the modem analog techniques to perform such a comparison because IKTF yields much worse RMSEP.

\subsection{Differences Among the Techniques}

For a thorough comparison, two additional aspects of the SST reconstruction techniques that have not been mentioned 

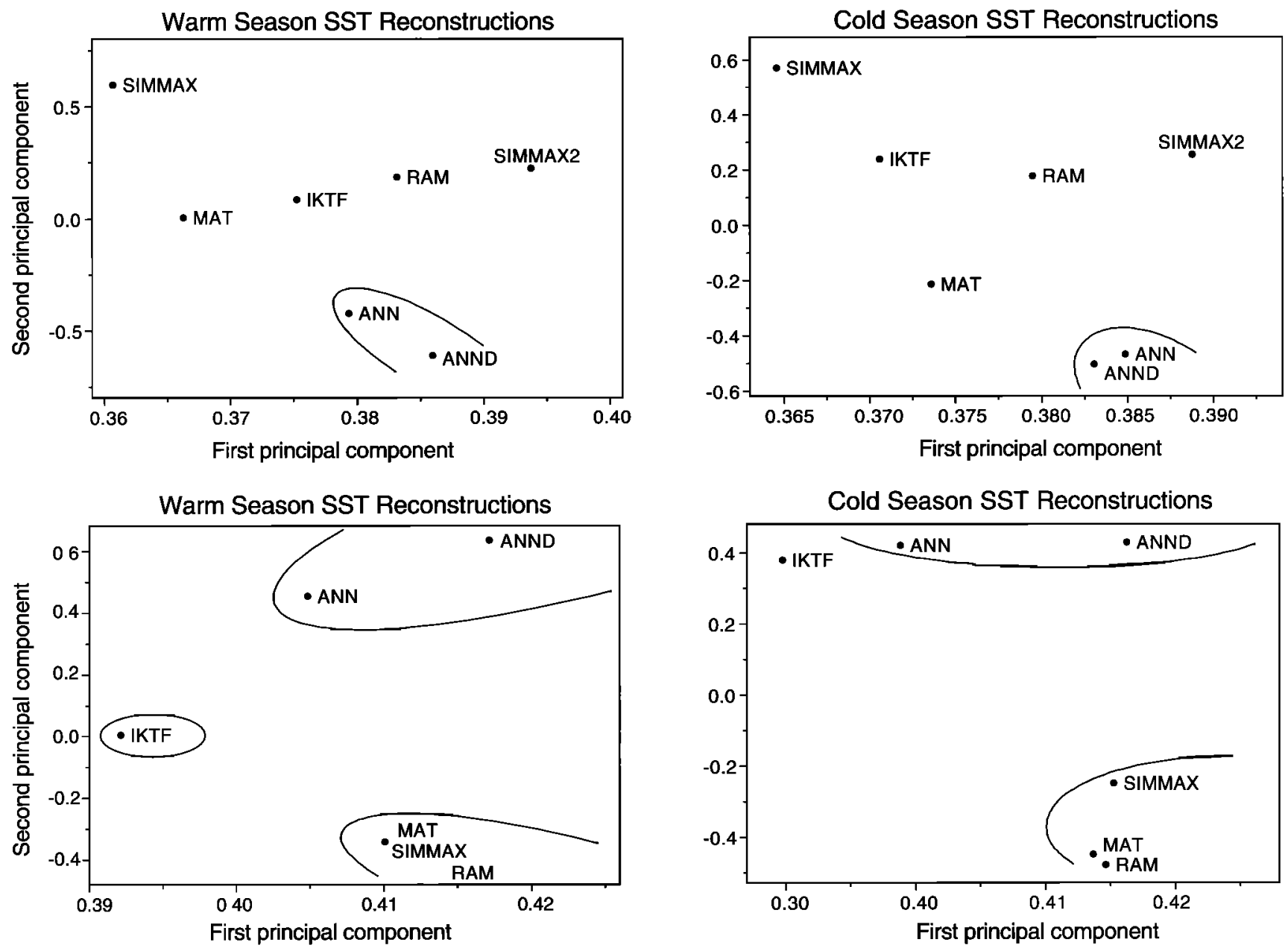

Figure 8. Results of a $Q$ mode principal component analysis of the SST reconstructions in (top) core PRB-12 (Figure 6) and (bottom) core V 25-59 (Figure 7) produced by the six SST prediction techniques. Techniques that yield similar SST reconstructions plot closely to each other in the diagram. SIMMAX2 denotes SIMMAX SST reconstructions where the two Caribbean core tops were removed from the training data sets.

before must be considered. These are the possibility of retrieving and analyzing separately the information on why the individual techniques lead to given SST predictions and the computational efficiency of both the training and the prediction process.

IKTF has a great advantage over the other methods by providing clear information on how the SST reconstructions are derived. An inspection of the principal component scores reveals groups of species forming "assemblages" typical for various SST regimes. Similarly, the modern analog techniques also provide valuable information about how SST estimates are derived. An examination of the "best analog samples" provides information on the modern environments or parts of the world ocean that are inhabited by plankton assemblages most similar to those found in a given fossil sample. None of the above can be applied to ANN, for although it is able to "learn" relationships among numbers in a remarkable

Table 4. Summary Comparison of the Six SST Prediction Techniques With Respect to Their Performance in Estimating SST in the Modern Ocean, in the Validation Data Set, and in the Fossil Data Set

\begin{tabular}{|c|c|c|c|c|c|c|}
\hline \multirow[b]{2}{*}{ Technique } & \multirow{2}{*}{$\begin{array}{l}\text { RMSEP Fit to } \\
\text { Modem Data }\end{array}$} & \multicolumn{2}{|c|}{$\begin{array}{l}\text { PRB-12 Validation of } \\
\text { Cold Season SST } \\
\end{array}$} & \multicolumn{3}{|c|}{ Application to Core V 25-59 } \\
\hline & & Values & Pattern & Termination I & OIS 2-5 Variation & OIS 6 Versus OIS 2 SST \\
\hline ANND & best $^{\mathrm{a}}$ & correct $^{\mathrm{a}}$ & $\operatorname{correct}^{\mathrm{a}}$ & abrupt & large & similar \\
\hline ANN & good & correct $^{\mathrm{a}}$ & $\operatorname{correct}^{\mathrm{a}}$ & abrupt & large & similar \\
\hline RAM & good & correct $^{\mathrm{a}}$ & weak & gradual & weak & much cooler \\
\hline SIMMAX & best $^{a}$ & correct $^{\mathrm{a}}$ & none $^{b}$ & gradual & weak & much cooler \\
\hline MAT & good & wrong $^{b}$ & weak & gradual & none & much cooler \\
\hline IKTF & worst ${ }^{b}$ & wrong $^{b}$ & wrong $^{\text {b }}$ & gradual & large & cooler \\
\hline
\end{tabular}

${ }^{\text {a }}$ Result is favorable.

${ }^{\mathbf{b}}$ Result is detrimental. 
manner, it does not provide many clues as to how these relationships are expressed.

When it comes to the incorporation of new samples into a training data set, the modem analog techniques offer the best solutions. Since these techniques do not generate any transfer functions, the expansion of the training database does not pose any computational effort at all. At the same time, the calculation of a particular estimate becomes computationally more demanding every time the database is expanded. A new set of transfer functions must be derived in the IKTF technique every time the training database is expanded; the calculation of the predictions is then straightforward and fast. As this technique employs only relatively simple calculations, the derivation of the transfer functions is not particularly computerintensive. This fact perhaps explains why this technique could be developed and used a decade earlier than MAT. ANN is by far the most computer-intensive technique; given the currently available computing speed, this technique is just on the edge of viability. While a trained neural network can be employed for paleotemperature predictions in a fraction of a second, the highly iterative training procedure is extremely time-consuming.

\subsection{Recommendations}

The present study provides the first meaningful evaluation of the various techniques' ability to produce accurate and reliable SST predictions. Arguably, the analysis of a single validation data set and a single fossil data set cannot provide a decisive tool for the ranking of the ability of the various techniques to reconstruct fossil SSTs. Nevertheless, when all comparisons in this study are taken into consideration (Table 4), it appears that artificial neural networks have at least the same potential for providing accurate SST estimates as the modern analog techniques. It is also clear that when it comes to accuracy and reliability of SST estimates, the IKTF technique is the worst. In fact, the only merit of this technique that may justify its continued use is the good understanding of the way it derives predictors from training data. In addition, our results seem to indicate that RAM may be a more suitable technique than the conventional MAT (not considering SIMMAX, which is adequate for the Holocene only). The fact that the predictions produced by ANN differ (at least in some cases) from those produced by modern analog techniques implies that both methods will have to be considered in further assessments of the reliability of SST estimates in the fossil record.

Acknowledgments. We thank Uwe Pflaumann for sharing his North Atlantic database. This work was financed in part by grant to B. A. M. from the Swedish Natural Science Research Council. During the preparation of this paper, M. K. was supported by a postdoctoral fellowship from STINT (The Swedish Foundation for International Cooperation in Research and Higher Education). J. N. thanks Göteborg University Marine Research Centre (GMF) and acknowledges the Royal Swedish Academy of Sciences (Hierta-Retzius' Foundation) for supplying equipment.

\section{References}

Bé, A. W. H., J. E. Damuth, L. Lott, and R. Free, Late Quaternary climatic record in western equatorial Atlantic sediment, Mem. Geol. Soc. Am., 145, 165-200, 1976.

Beale, R., and T. Jackson, Neural Computing: An Introduction, 240 pp., Adam Hilger, Bristol, England, 1990.

Birks, H. J. B., Quantitative palaeoenvironmental reconstructions, in Statistical Modelling of Quaternary Science Data, Tech Guide 5, edited by D. Maddy and J. S. Brew, pp. 161254, Quat. Res. Assoc., Cambridge, England, 1995.

Climate: Long-Range Investigation, Mapping, and Prediction Project Members, The last interglacial ocean, Quat. Res , 21, 123-224, 1984.

da Silva, A., C. C. Young-Molling, and S. Levitus, Atlas of Surface Marine Data 1994, vol I, Algorithms and Procedures, NOAA Atlas NESDIS 6, U.S. Dep. of Commer., Washington, D. C., 1994.

Hutson, W. H., Transfer functions under no-analog conditions: Experıments with Indian Ocean planktonic foraminifera, Quat. Res., 8, 355$367,1977$.

Hutson, W. H., The Agulhas current during the late Pleistocene: Analysis of modem faunal analogs, Science, 207, 64-66, 1980.

Imbrie, J., and N. G. Kipp, A new micropaleontological method for quantitative paleoclimatology: Application to a late Pleistocene Caribbean core, in The Late Cenozoic Glacial Ages, edited by K. K. Turekıan, pp. 71-181, Yale Univ. Press, New Haven, Conn., 1971.

Le, J., Palaeotemperature estimation methods: Sensitivity test on two western equatorial $\mathrm{Pa}$ cific cores, Quat. Sci. Rev., 11, 801-820, 1992.
Le, J., and N. J. Shackleton, Reconstructing paleoenvironment by transfer function: Model evaluation with simulated data, Mar Micropaleontol, 24, 187-199, 1994.

Levitus, S., Climatological atlas of the world ocean, NOAA Prof. Pap. 13, 173 pp., U.S. Govt. Print. Off., Washington, D. C., 1982.

Malmgren, B. A., and U. Nordlund, Application of artificial neural networks to chemostratigraphy, Paleoceanography, 11, 505-512, 1996.

Malmgren, B. A., and U. Nordlund, Application of artificial neural networks to paleoceanographic data, Palaeogeogr. Palaeoclimatol. Palaeoecol., 136, 359-373, 1997.

McIntyre, A., W. F. Ruddiman, K. Karlin, and A. C. Mix, Surface water response of the equatorial Atlantic Ocean to orbital forcing, Paleoceanography, 4, 19-55, 1989.

Nyberg, J., A. Kuijpers, B. A. Malmgren, and H. Kunzendorf, Late Holocene changes in precipitation and hydrography recorded in marine sediments from the northeastern Caribean Sea, Quat Res., 56, 87-102, 2001.

Ortiz, J. D., and A. C. Mix, Comparison of Imbrie-Kipp transfer function and modern analog temperature estimates using sediment trap and core top foraminiferal faunas, Paleoceanography, 12, 175-190, 1997

Overpeck, J. T., R. S. Webb, and T. Webb, III, Mapping eastem North American vegetation change of the past $18 \mathrm{ka}$ : No-analogs and the future, Geology, 20, 1071-1074, 1992.

Pflaumann, U., J. Duprat, C. Pujol, and L. Labeyrie, SIMMAX: A modem analog technique to deduce Atlantic sea surface temperatures from planktonic foraminifera in deep-sea sediments, Paleoceanography, $11,15-35,1996$.

Prell, W. L., The stability of low-latitude sea-sur- face temperatures: An evaluation of the CLIMAP reconstruction with emphasis on the positive SST anomalies, Rep. TR025, U.S. Dep. of Energy, Washington, D. C., 1985.

ter Braak, C. J. F., and H. van Dam, Inferring $\mathrm{pH}$ from diatoms: A comparison of old and new calibration methods, Hydrobiologla, 178, 209-223, 1989.

Waelbroeck, C., L. Labeyrie, J.-C. Duplessy, J. Guiot, M. Labracherie, H. Leclaire, and J. Duprat, Improving past sea surface temperature estimates based on planktonic fossil faunas, Paleoceanography, 13, 272-283, 1998.

Wasserman, P D., Neural Computing - Theory and Practice, 230 pp., Van Nostrand Reinhold, New York, 1989.

M. Kucera, Department of Geology, Royal Holloway College, University of London, Egham Hill, Egham TW20 0EX, Surrey, England, UK. (m.kucera@gl.rhul.ac.uk)

B. A. Malmgren and J. Nyberg, Department of Earth Sciences-Marine Geology, Göteborg University, Box 460, Göteborg, SE-405 30 Sweden. (bjorn.malmgren@marine-geology. gu.se; johann@gvc.gu.se)

C. Waelbroeck, Laboratoire des Sciences du Climat et de l'Environnement, Laboratoires mixte CNRS-CEA, Domaine du CNRS, 1 Avenue de la Terasse, Batiment 12, Gif-sur-Yvette Cedex 91198, France. (Claire.Waelbroeck@Isce. curs-gif.fr)

(Received July 11, 2000; revised May 2, 2001; accepted May 25, 2001.) 